\title{
IMPROVING COMMUNICATION WITHIN THE INTERDISCIPLINARY TEAM MONITORING YOUNG WOMEN WITH ONCO-GYNECOLOGICAL PATHOLOGY IN ROMANIA
}

\author{
IOAN LANCRAJAN ${ }^{1}$, IOAN LISENCU ${ }^{2}$, LAURENTIU IGNAT ${ }^{2}$, \\ RARES TRISCA ${ }^{2}$, MADALINA COMAN ${ }^{1}$, FLOAREA MOCEAN ${ }^{1}$
}

\author{
${ }^{1}$ Public Health and Management Department, Iuliu Hatieganu University of \\ Medicine and Pharmacy, Cluj-Napoca, Romania \\ ${ }^{2}$ Oncology Department, Iuliu Hatieganu University of Medicine and Pharmacy, \\ Cluj-Napoca, Romania
}

\begin{abstract}
Background. The quality of medical care, as well as the application of effective treatments in the management of patients with gynecologic neoplasm, is of great importance. Finding new and efficient ways of communication between the doctors involved in the multidisciplinary team for the management of the disease, from the diagnosis to the reintegration into society, would help improve the quality of comprehensive patient care.

Objective. The objective of the study was to assess the collaboration of family physicians with specialists treating patients suffering from gynecologic cancer, in order to improve the relationship between them via electronic communication.

Study design. We conducted a descriptive, transversal study on 353 family physicians and 37 specialist doctors from Romania, between January and June 2015. For statistical data analysis, R for Data Analysis and Graphics version 3.2.1 was used.

Results. Most of the family physicians and specialist doctors believed that they provided the best care that they could, but consider that a multidisciplinary approach using online communication methods, in which doctors collaborate among each other, is needed.

Conclusions. Finding a simple, efficient and modern means of communication is essential in order to increase the efficiency of medical care overall.
\end{abstract}

Keywords: multidisciplinary collaboration, oncology, communication

\section{Introduction}

The quality of medical care, as well as the application of effective treatments in the management of patients with gynecologic oncological conditions is of great importance $[1,2,3]$. Finding new and efficient ways of communication between the doctors involved in the multidisciplinary team for the management of the disease, from the diagnosis to the reintegration into society, would help improve the quality of comprehensive patient care. For the purpose of optimizing the current management systems, the patients' needs and their rights must be taken into account, making them a top priority for the health care provider [4]. Minimizing the costs, the types and number of overlapping or disjointed services

Manuscript received: 08.12.2017

Received in revised form: 15.02.2018

Accepted: 07.03.2018

Address for correspondence: madalina.coman@publichealth.ro through collaboration is ideal for improving the quality of care provided [5]. Also, in order to have successful programs, interventions and campaigns, good management decisions from multidisciplinary teams need to be taken $[6,7]$.

Management programs can increase the quality of care offered to patients suffering from chronic diseases, such as cancers of the female reproductive system in young women $[1,8,9]$. The best outcomes of the management program comes from the successful training of clinicians with the purpose of achieving the desired results in female patients at risk of developing reproductive cancer [10]. Advances in the diagnosis and treatment of cancer lead to a higher number of survivors and a better quality of life $[1,11]$. However, the tools for recognizing lasting adverse effects of cancer therapy have to be further developed, in order to better treat or prevent them [8]. Improving communication within 
the interdisciplinary team (family physicians, gynecologists, pathologists, surgeons, oncologists, radiotherapists, psychologists), who monitor the young female patients with gynecologic neoplasma is of utmost importance for managing cases for both newly diagnosed patients and the ones who are already in follow-up $[8,12,13]$. Primary care in Romania would require special attention through the specialists' role of being the first to come into direct contact with the patients. Their opinions can have a great impact on screening programs, as well as on tracking the progress of the patients' treatment.

Research indicates that better communication between specialists and family physicians leads to reduced costs in the healthcare system $[14,15,16]$. Electronic communication between medical staff in specialist care and primary care alone can double the savings in healthcare expenditure [17]. Such services have the potential to reduce the frequency of the medical services usage and thus, have the potential to lower the costs associated with the use of medical services $[5,18]$. The costs associated with cancer in Europe were 126 million euros and studies show that these are constantly increasing, therefore such services are necessary to help stabilize the economy of the healthcare system [18]. To the best of our knowledge, in Romania there are no studies on the costs imposed on the healthcare system with regard to diseases in the gynecologic oncology spectrum, but we have every reason to believe that Romania follows the same trend as other European countries, where improving the communication between specialists and family physicians, as well as using methods of electronic communication is recommended.

According to our knowledge, in Romania there are no studies on interdisciplinary relationships between family physicians and specialists in gynecologic oncology. Likewise, as far as we know, in Romania there are no management protocols that encourage interdisciplinary collaborations and promote better communication among medical staff [19].

Taking all this into account, this study aims to assess the collaboration of family physicians with specialists treating patients suffering from gynecologic oncological conditions, with the purpose of improving the relationship between them via electronic communication.

\section{Methods}

The data was collected using a descriptive transversal study which was implemented online for family physicians (questionnaire sent via e-mail) and offline for the specialists from The Oncology Institute "Prof. Dr. Ion Chiricuță” Cluj-Napoca.

The questionnaire consisted of a set of 15 closedended questions which assessed the current and future level of communication between family physicians from the North West and Center Region and specialists from The Oncology Institute "Prof. Dr. Ion Chiricuță" ClujNapoca. The questionnaire assessed: (i) the involvement of family physicians in monitoring patients diagnosed with conditions from the genital and breast cancer spectrum, (ii) the future needs in collaborating with the specialists to improve medical care in order to improve the quality of life of patients on every aspect (social, family, sexual). The target group for this study consisted of family physicians from the North West and Center Region and specialists from The Oncology Institute "Prof. Dr. Ion Chiricuță" ClujNapoca (oncologists, gynecologic oncologists, surgeons, radiotherapists). A database with the e-mail addresses of family physicians from 11 counties from the North West and Center Region was built for this study. Out of the 2480 family physicians from the 11 counties, 693 were excluded (519 do not own an e-mail address, and 174 e-mail addresses were not valid) therefore, 1787 questionnaires were sent via e-mail. For the specialists at The Oncology Institute "Prof. Dr. Ion Chiricuță" Cluj-Napoca the questionnaires were distributed in written form within the institute.

The study was approved by the Ethics Committee of The Oncology Institute "Prof. Dr. Ion Chiricuță", ClujNapoca.

For statistical data analysis, the $\mathrm{R}$ system of statistical calculations graphics version 3.2.1/ $\mathrm{R}$ for Data Analysis and Graphics version 3.2.1 was used.

\section{Results}

Out of 1787 questionnaires sent online, the response rate was 353 family physicians (19\%). From the specialists from The Oncology Institute "Prof. Dr. Ion Chiricuță" Cluj-Napoca who were surveyed, 37 doctors (oncologists, gynecologists, surgeons, radiotherapists) responded.

Most of the family physicians ( $85 \%)$ had treated less than 10 women with such conditions, $11 \%$ had between $10-20$ such patients, and 3\% had over 20 patients in this category. As for the specialists, $53 \%$ of them reported that over $50 \%$ of the cases treated at The Oncology Institute "Prof. Dr. Ion Chiricuță" were cases of patients with genital or breast cancer conditions. Most of the doctors (61\%) claimed that most of the patients they treated suffered from breast cancer, followed by cervical cancer (29\%).

The findings of the questionnaire showed that $49 \%$ of the family physicians believed that they contributed to a small extent in the diagnosis and care of cancer patients under treatment, but $84 \%$ of the sample believed that the best treatment possible was applied in a multidisciplinary setting. Of those surveyed, $97 \%$ claimed that they would like another future collaboration with specialists from the Oncology Institute "Prof. Dr. Ion Chiricuță" Cluj-Napoca. Also, 91\% have expressed their interest in attending a conference on the latest treatment updates for genital and breast cancer conditions, while $93 \%$ reported that they were interested in presentations on methods of monitoring and caring for patients after cancer treatment. Moreover, $88 \%$ claimed that they would be interested in participating in the development of guidelines for genital and breast cancers, 
and $91 \%$ would agree to provide primary care to patients after having undergone cancer treatment. In terms of the evolution of the patients' condition after treatment, $64 \%$ responded that they had a good progress, and $43 \%$ reported a better collaboration with the specialists, while $14 \%$ said that they did not collaborate at all (Table I).

A large percentage (73\%) of the specialists claimed that the involvement of family physicians was important for the treatment of patients, and 95\% stated that it was very important for them that the patients receive adequate primary care. Also, $65 \%$ of the specialists believed that it was extremely important that some of the presentations on genital and breast cancer conditions be available to family physicians as well. More than $81 \%$ of the specialists believed that several post cancer treatment conditions could be treated by family physicians, with $100 \%$ of the respondents being willing to provide advice and counseling to the primary care physicians. Also, $95 \%$ of them considered that some good practice guidelines would be useful in the post cancer treatment and that family physicians could benefit from them. Out of the total sample, $62 \%$ of the respondents believed to a great extent that a broader collaboration with family physicians would be useful, and $54 \%$ of them considered setting up an online communication system for specialists and family physicians to be just as useful (Table II).

Table I. Questions addressed to the family physicians.

\begin{tabular}{|c|c|c|c|c|c|}
\hline Question & To a large extent & To a small extent & Not at all & Insufficient & Not applicable \\
\hline $\begin{array}{l}\text { Have you actively participated in explaining the } \\
\text { diagnosis and in taking care of the patients after their } \\
\text { cancer treatment? }\end{array}$ & $146(41 \%)$ & $172(49 \%)$ & - & $33(9 \%)$ & 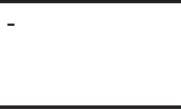 \\
\hline $\begin{array}{l}\text { To what extent have you and your patients been } \\
\text { convinced that the best treatment has been applied in a } \\
\text { multidisciplinary setting? }\end{array}$ & $296(84 \%)$ & $36(10 \%)$ & $3(1 \%)$ & - & $14(4 \%)$ \\
\hline $\begin{array}{l}\text { To what extent would you want a future collaboration } \\
\text { regarding your patients' treatment at IOCN? }\end{array}$ & $343(97 \%)$ & $7(2 \%)$ & $0(0 \%)$ & - & - \\
\hline $\begin{array}{l}\text { To what extent would you be interested in attending } \\
\text { a conference on the updates of treatment for female } \\
\text { reproductive cancer spectrum? }\end{array}$ & $329(91 \%)$ & $15(4 \%)$ & $2(1 \%)$ & - & - \\
\hline $\begin{array}{l}\text { To what extent would you be interested in developing } \\
\text { some guidelines for treating cancers in the female } \\
\text { reproductive cancer spectrum? }\end{array}$ & $310(88 \%)$ & $35(10 \%)$ & $4(1 \%)$ & - & - \\
\hline $\begin{array}{l}\text { To what extent would you be interested in attending } \\
\text { presentations on methods of caring and monitoring } \\
\text { patients after cancer treatment? }\end{array}$ & $326(93 \%)$ & $20(6 \%)$ & $1(0 \%)$ & - & - \\
\hline $\begin{array}{l}\text { To what extent would you be willing to provide primary } \\
\text { care to patients after treatment? }\end{array}$ & $321(91 \%)$ & $27(8 \%)$ & $4(1 \%)$ & - & - \\
\hline Question & Very good & Good & Satisfactory & I did not collaborate & \\
\hline $\begin{array}{l}\text { How would you rate the progress of your patients after } \\
\text { treatment? }\end{array}$ & $70(20 \%)$ & $226(64 \%)$ & $52(5 \%)$ & - & \\
\hline $\begin{array}{l}\text { How would you rate your collaboration with the } \\
\text { specialists at IOCN? }\end{array}$ & $86(24 \%)$ & $153(43 \%)$ & $53(15 \%)$ & $51(14 \%)$ & \\
\hline
\end{tabular}

Table II. Questions addressed to the specialists at IOCN (surgeons, oncologists, radiotherapists).

\begin{tabular}{|c|c|c|c|c|c|c|c|}
\hline \multicolumn{3}{|l|}{ Question } & \multicolumn{2}{|c|}{ Very important } & \multicolumn{2}{|c|}{ Important } & Less important \\
\hline \multicolumn{3}{|c|}{$\begin{array}{l}\text { How important do you think the contribution of family physicians in caring for cancer } \\
\text { patients' pre and post treatment is? }\end{array}$} & \multicolumn{2}{|c|}{$27(73 \%)$} & \multicolumn{2}{|c|}{$7(19 \%)$} & $2(5 \%)$ \\
\hline \multicolumn{3}{|c|}{ How important would it be for you that your patients receive adequate primary care? } & \multicolumn{2}{|c|}{$35(95 \%)$} & \multicolumn{2}{|l|}{$2(5 \%)$} & $0(0 \%)$ \\
\hline \multicolumn{3}{|c|}{$\begin{array}{l}\text { How important do you think presentations for family physicians on frequent cancer } \\
\text { treatment complications would be?" }\end{array}$} & \multicolumn{2}{|c|}{$26(65 \%)$} & \multicolumn{2}{|c|}{$13(35 \%)$} & $0(0 \%)$ \\
\hline \multicolumn{3}{|c|}{ Question } & \multicolumn{2}{|c|}{ To a large extent } & \multicolumn{2}{|c|}{ To a small extent } & Not at all \\
\hline \multicolumn{3}{|c|}{$\begin{array}{l}\text { "To what extent do you think that some post cancer treatment complications could be } \\
\text { solved at the family physician's office?" }\end{array}$} & \multicolumn{2}{|c|}{$30(81 \%)$} & \multicolumn{2}{|c|}{$7(19 \%)$} & $0(0 \%)$ \\
\hline \multicolumn{3}{|c|}{$\begin{array}{l}\text { To what extent would you be willing to offer advice to the family physician when issues } \\
\text { arise with shared patients? }\end{array}$} & \multicolumn{2}{|c|}{$37(100 \%)$} & \multicolumn{2}{|l|}{$0(0 \%)$} & $0(0 \%)$ \\
\hline \multicolumn{3}{|c|}{$\begin{array}{l}\text { To what extent do you think that developing guidelines for post cancer treatment could be } \\
\text { useful at the level of the family physician's office? }\end{array}$} & \multicolumn{2}{|c|}{$35(95 \%)$} & \multicolumn{2}{|l|}{$1(3 \%)$} & $0(0 \%)$ \\
\hline Question & Very beneficial & \multicolumn{2}{|c|}{ Beneficial } & \multicolumn{2}{|c|}{ Pretty beneficial } & \multicolumn{2}{|c|}{ It wouldn't bring any benefi } \\
\hline $\begin{array}{l}\text { How would you rate a wider collaboration with family physicians on } \\
\text { common patients? }\end{array}$ & $23(62 \%)$ & \multicolumn{2}{|c|}{$13(35 \%)$} & \multicolumn{2}{|l|}{$1(3 \%)$} & \multicolumn{2}{|c|}{$0(0 \%)$} \\
\hline $\begin{array}{l}\text { How would you rate the establishment of an online communication } \\
\text { system between you and family physicians regarding shared patients? }\end{array}$ & $20(54 \%)$ & \multicolumn{2}{|c|}{$15(41 \%)$} & \multicolumn{2}{|l|}{$1(3 \%)$} & \multicolumn{2}{|l|}{$1(3 \%)$} \\
\hline
\end{tabular}




\section{Discussion and conclusions}

The results of this study show that most of family physicians who have come into contact with patients with neoplastic abnormalities being treated at the Oncology Institute "Prof. Dr. Ion Chiricuţă" Cluj-Napoca, believe that the best treatment with the highest level of patient satisfaction has been applied in a multidisciplinary setting. However, they did not actively take part in elaborating the diagnosis and post treatment care for patients.

Most of the specialists at The Oncology Institute "Prof. Dr. Ion Chiricuţă" Cluj Napoca, collaborated well with family physicians and believe that their involvement in the treatment and care of cancer patients, and adequate primary care is essential. Moreover, they believe that finding a communication tool and organizing some conferences and courses for family physicians would contribute to increasing the efficiency of future medical care. They are also willing to offer advice to primary care physicians whenever necessary.

These findings are in line with other findings from previous research studies, which show that a multidisciplinary team which collaborates effectively is needed for a comprehensive and optimal treatment for the patient $[3,10,11,13]$.

\section{Limitations and recommendations}

The limitations of this study consists of the fact that only the North West and Center Region was taken into account for this study, therefore our findings cannot be extrapolated to the entire country level. Future studies should focus on covering a larger area of the country in order to be able to compare the findings among counties. Another limitation would be the fact that the questionnaire was sent online and some of the possible participants might have been lost because they did not have valid e-mail addresses or because they don't use the internet for the purpose of online communication. However, for the purpose of this study it was important for our participants to use the internet for online communication, since it pilots the idea of multidisciplinary work teams, which most times require to work remotely and use the internet as means for online communication. A recommendation for future studies would be to have another component of paperbased questionnaire to be applied to doctors during their office hours, in order to back-up the data collected via the online questionnaire.

After conducting this study, we believe that finding simple, efficient and modern tools of communication between physicians is essential in order to increase the efficiency of medical care overall and to create multidisciplinary teams. This could include an online platform of communication through which physicians can exchange ideas and examples of good practices to be used by multidisciplinary teams.

Another important recommendation would be the organization of symposiums and conferences on the treatment and care of patients diagnosed with reproductive cancers where family physicians and oncologists can interact, exchange information and create networking links.

\section{Acknowledgments}

We kindly acknowledge Marisa Perry for proofreading and helping with the translation of this manuscript.

\section{References}

1. Fleisch MC, Pantke P, Beckmann MW, Schnuerch HG, Ackermann R, Grimm MO, et al. Predictors for long-term survival after interdisciplinary salvage surgery for advanced or recurrent gynecologic cancers. J Surg Oncol. 2007;95(6):476-484

2. Manton K, Akushevich I, Kravchenko J. Cancer mortality and morbidity patterns in the US population: an interdisciplinary approach. Springer; 2009. p. 280.

3. Granda-Cameron C, DeMille D, Lynch M, Huntzinger C, Alcorn T, Levicoff J, Mintzer D. An Interdisciplinary Approach to Manage Cancer Cachexia. Clin J Oncol Nurse. 2010; 14(1):72-80.

4. Berkowitz E. Essentials of Health Care Marketing. Burllington. Jones \& Bartlett Publishers; 2016. p. 95.

5. Bertakis KD, Azari R. Patient-centered care is associated with decreased health care utilization. J Am Board Fam Med. 2011;24(3):229-239.

6. Pricopie R. Policy Dialog: the Missing Link in the 2008 Romanian Human Papillomavirus (Hpv) Vaccination Program. Transylv Rev Adm Sci. 2009;92-109.

7. Mocean F. Marketing si Management. Cluj-Napoca: Editura Medicala Universitara "Iuliu Hatieganu"; 2007. p. 31.

8. Ball C, Madden JE. Update on cervical cancer screening. Current diagnostic and evidence-based management protocols. Postgrad Med. 2003;113(2):59-64, 70.

9. Lash TL, Thwin SS, Yood MU, Geiger AM, Bosco J, Quinn VP, et al. Comprehensive evaluation of the incidence of late effects in 5-year survivors of breast cancer. Breast Cancer Res Treat. 2014;144(3):643-663.

10. Valdivieso M, Kujawa AM, Jones T, Baker LH. Cancer survivors in the United States: a review of the literature and a call to action. Int J Med Sci. 2012;9(2):163-173.

11. Miles A, Mezzich J. The care of the patient and the soul of the clinic: person-centered medicine as an emergent model of modern clinical practice. Int J Pers Cent Med. 2011;1(2): Available from: http://www.ijpcm.org/index.php/IJPCM/article/view/61.

12. Bitton A, Ratcliffe HL, Veillard JH, Kress DH, Barkley S, Kimball M, et al. Primary Health Care as a Foundation for Strengthening Health Systems in Low- and Middle-Income Countries. J Gen Intern Med. 2017;32(5):566-571.

13. Davidson GH, Austin E, Thornblade L, Simpson L, Ong $\mathrm{TD}$, Pan $\mathrm{H}$, et al. Improving transitions of care across the spectrum of healthcare delivery: A multidisciplinary approach to understanding variability in outcomes across hospitals and skilled nursing facilities. Am J Surg. 2017;213(5):910-914.

14. Kripalani S, LeFevre F, Phillips C, Williams MV, Basaviah P, Baker DW. Deficits in communication and information transfer between hospital-based and primary care physicians: implications for patient safety and continuity of care. JAMA. 2007;297(8):831841.

15. Hansen LO, Greenwald JL, Budnitz T, Howell E, Halasyamani L, Maynard G, et al. Project BOOST: effectiveness 
of a multihospital effort to reduce rehospitalization. J Hosp Med. 2013;8(8):421-427.

16. Meiklejohn JA, Mimery A, Martin JH, Bailie R, Garvey G, Walpole ET, et al. The role of the GP in follow-up cancer care: a systematic literature review. J Cancer Surviv. 2016;10(6):990 1011.

17. Hillestad R, Bigelow J, Bower A, Girosi F, Meili R, Scoville $\mathrm{R}$, et al. Can electronic medical record systems transform health care? Potential health benefits, savings, and costs. Health Aff (Millwood). 2005;24(5):1103-1117.

18. Luengo-Fernandez R, Leal J, Gray A, Sullivan R. Economic burden of cancer across the European Union: a population-based cost analysis. Lancet Oncol. 2013;14(12):1165-1174.

19. Triff D, Triff Z, Tigan S, Achimas Cadariu A. Survey on the Use of Electronic Health Records by Occupational Medicine Physicians. Appl Med Inform. 2012;30:7-17. 